\title{
Nitrogen Uptake in Soils under Different Water Table Depths
}

\author{
J. D. Owusu-Sekyere ${ }^{1}$ and E. Obeng Bekoe ${ }^{2}$ \\ Department of Agricultural Engineering, School of Agriculture, University of Cape \\ Coast, Cape Coast, Ghana \\ CSIR-Water Research Institute, P. O. Box M. 32, Accra, Ghana \\ Corresponding author; E-mail: jaydosus@yahoo.com
}

\begin{abstract}
A mathematical model was used to examine the interactions of $\mathrm{NH}_{4}^{+}$transport to rice roots, as well as to calculate root length densities required to relate $\mathrm{N}$ uptake to concentrations of $\mathrm{NH}_{4}^{+}$in solution around the rooting medium for three water treatments: water table $30 \mathrm{~cm}$ below the surface, $15 \mathrm{~cm}$ below the surface and a flooded system. Measured uptake was greatest for the plants under the $30 \mathrm{~cm}$ treatment, followed by the 15 $\mathrm{cm}$ treatment, then the flooded treatment. Solution concentrations were highest under the flooded treatment followed by the $30 \mathrm{~cm}$ treatment, then the $15 \mathrm{~cm}$ treatment. Calculated root length densities were greatest for the plants under the $30 \mathrm{~cm}$ water table treatment, followed by those under the $15 \mathrm{~cm}$ treatment, then the flooded treatment. Measured root length densities were similarly greatest for the plants under the $30 \mathrm{~cm}$ water table treatment, followed by those under the $15 \mathrm{~cm}$ water table depth treatment, then the flooded treatment. However, differences between measured and calculated root length densities became significant for all treatments after 30 days of treatment imposition. Transport rates varied with treatments but uptake rates did not reflect these differences in transport rates, thus, transport through the growth medium did not limit uptake of nitrogen by the plants.
\end{abstract}

\section{Introduction}

Nitrogen availability is often the main factor limiting the realization of yield potentials in irrigated rice, and, according to Cassman $e t$ al. (1997), yield components are closely associated with the nitrogen supply at each growth period. Moreover, active absorption and metabolism of nitrogen result in large increase in dry weight, tillering, height and leaf area. Growth differences under a water table control system might, therefore, be due to differences in nitrogen uptake-limiting processes.

According to Kirk \& Solivas (1997) root properties and transport through the soil can limit nitrogen uptake for rice growing in flooded soil. Rooting characteristics, however, vary with the depth of water table imposed and under lower water tables, there exist gradients of soil moisture content between the soil surface and the water table, implying differences in rates of solute transport through the soil and, hence, possibly of nutrient transport to absorbing roots (Owusu-Sekyere, 2005).

Kirk \& Solivas (1997) developed a model to determine the extent to which root properties and transport through the soil limit nitrogen uptake by lowland rice. This paper presents a modification of the model, uses results obtained from Owusu-Sekyere (2005) to examine interactions between $\mathrm{NH}_{4}{ }^{+}$transport to the roots, root length densities under three water regimes, and, finally, compares the models' calculated root lengths densities to experimentally obtained ones according to Owusu-Sekere (2005). 


\section{Materials and methods}

Modification of the Kirk and Solivas model

In this section the Kirk \& Solivas (1997) model and the modifications made are presented.

Equations and assumptions. The time rate of uptake of $\mathrm{NH}$ by roots is given by:

$$
\frac{\mathrm{dU}}{\mathrm{dt}}=2 \pi \mathrm{aFL}_{\mathrm{v}} \mathrm{V}
$$

where $\mathrm{a}$ is the mean root radius and $\mathrm{U}$ is uptake in moles per unit area, $\mathrm{F}$ is moles per unit time, $\mathrm{V}$ is volume and $\mathrm{Lv}$ is length per unit volume. The terms in Equation 1 and subsequent equations are obtained as given below:

$\mathrm{F}=\alpha \mathrm{C}_{\mathrm{La}}$

where $\mathrm{C}_{\mathrm{La}}$ is the concentration in moles per unit volume of $\mathrm{NH}_{4}^{+}$in solution at the root surface and $\alpha$ is the root absorbing power. $\alpha=\mathrm{F}_{\max } /\left(\mathrm{K}_{\mathrm{M}}+\mathrm{C}_{\mathrm{La}}\right)$

where $\mathrm{F}_{\text {max }}$ is the maximum influx into the roots and $\mathrm{K}_{\mathrm{M}}$ the Michelis constant for $\mathrm{NH}_{4}^{+}$ absorption.

$$
\mathrm{C}_{\mathrm{La}}=\bar{C}_{L}\left[1-\frac{1}{2} \frac{\alpha \mathrm{a}}{\mathrm{Db}}+\frac{\mathrm{x}^{2} \frac{\alpha \mathrm{a}}{\mathrm{Db}}}{\left(\mathrm{x}^{2}-\mathrm{a}^{2}\right)} \ln \frac{\mathrm{x}}{\mathrm{a}}\right]^{-1}
$$

where $\mathrm{x}$ is the radius of the $\mathrm{NH}_{4}^{+}$depletion zone and $\overline{\mathrm{C}_{\mathrm{L}}}$ the mean concentration in solution. $\mathrm{D}$ is the soil $\mathrm{NH}_{4}^{+}$diffusion coefficient, and b is the soil $\mathrm{NH}_{4}^{+}$buffer power.

$$
\mathrm{D}=\mathrm{D}_{\mathrm{L}} \theta \mathrm{f}_{\mathrm{L}} / \mathrm{b}
$$

where $\mathrm{D}_{\mathrm{L}}$ is the $\mathrm{NH}_{4}^{+}$diffusion coefficient in water, $\theta$ is the soil water fraction by volume, and $\mathrm{f}_{\mathrm{L}}$ is the diffusion impedance factor.

Kirk \& Soliva (1997) assumed a constant moisture content but in this work moisture varies with depth above the water table. It is represented by:

$$
\theta_{\mathrm{z}}=\theta_{0}+\left(\theta_{\text {sat }}-\theta_{0}\right) \mathrm{z} / \mathrm{z}_{\text {sat }} \quad 0<\mathrm{z}<\mathrm{z}_{\text {sat }}(6)
$$
where $\mathrm{z}_{\text {sat }}$ is the depth of the water table and $\theta_{z}, \theta_{0}$ and $\theta_{\text {sat }}$ are the moisture contents at depth $\mathrm{z}$, the soil surface $(\mathrm{z}=0)$ and the water table $\left(\mathrm{z}=\mathrm{z}_{\mathrm{sat}}\right)$, respectively. Root density was constant in the Kirk \& Soliva (1997) model but is varied here and represented according to Tinker \& Nye (2000):

$$
\mathrm{P}_{\mathrm{z}}=1-\exp (-\beta \mathrm{z})
$$

where $\mathrm{P}_{\mathrm{z}}$ is the fraction of the total root mass above depth $\mathrm{z}$ and $\beta$ is a coefficient such that $1 / \beta$ is the depth containing $63 \%$ of the total root mass.

To allow for varying moisture and root length density with depth the soil was divided into small intervals, over which moisture and root length could be taken to be effectively constant. Total root $\mathrm{N}$ uptake by the root system $(\mathrm{dU} / \mathrm{dt})_{\text {total }}-$ which is found from the differentiated logistic curve for $\mathrm{N}$ uptake (Equation 12) - was then divided across the soil-depth layers according to the distribution of root mass. Hence, from Equation (7), the ratio of uptake in the $i^{\text {th }}$ depth layer (where $\mathrm{i}=1$ is the soil surface layer) and above to the total uptake is:

$$
\frac{\sum_{\mathrm{i}=\mathrm{i}}^{\mathrm{i}=1}(\mathrm{dU} / \mathrm{dt})_{\mathrm{i}}}{(\mathrm{dU} / \mathrm{dt})_{\text {total }}}=1-\exp \left(-\beta \mathrm{z}_{\mathrm{i}}\right)
$$

Equation (3) can be expanded as follows:

$$
\begin{aligned}
& \sum_{\substack{i=i \\
i=1}}^{i=1}(d U / d t)_{i}=(d U / d t)_{i}+(d U / d t)_{i-1}+ \\
& \sum_{i=i-2}^{i=1}(d U / d t)_{i}=\left\{1-\exp \left(-\beta z_{i}\right)\right\}(d U / d t)_{\text {total }} \\
& \text { also }
\end{aligned}
$$


The flooded cores were saturated throughout, i.e. $\theta=\theta_{\mathrm{s}}=0.375$ at $0<\mathrm{z}<40$ $\mathrm{cm}$. In the cores with the water table at 15 $\mathrm{cm}, \theta=0.34$ at $\mathrm{z}=0$ and $\theta=\theta_{\mathrm{s}}$ at $15 \mathrm{~cm}<$ $\mathrm{z}<40 \mathrm{~cm}$, and in those with the water table at $30 \mathrm{~cm}, \theta=0.14$ at $\mathrm{z}=0$ and $\theta=\theta_{\mathrm{s}}$ at 30 $\mathrm{cm}<\mathrm{z}<40 \mathrm{~cm}$. Between $\mathrm{z}=0$ and $\mathrm{z}=\mathrm{z}_{\text {sat, }}$ $\theta$ is given by Equation (6).

Diffusion impedance factor was obtained as follows (Tinker \& Nye, 2000): the approximation $\mathrm{f}_{\mathrm{L}=} \mathrm{q}$ is reasonable over the range of soil moisture contents in the present experiments. Soil $\mathrm{NH}_{4}^{+}$buffer power, $\mathrm{b}$, is given by

$$
\mathrm{b}=\theta+\rho \mathrm{Rm} / \mathrm{C}_{\mathrm{L}}
$$

where $\mathrm{m}=56.55$ with $\mathrm{C}_{\mathrm{L}}$ in $\mathrm{mM}$, and $\mathrm{R}=$ $0.0192 \mathrm{~kg}$ vermiculite $\mathrm{kg}^{-1}$ soil.

The mean root radius reported by Kirk $\&$ Soliva (1997) for rice grown in flooded soil under comparable conditions, $0.11 \mathrm{~mm}$ was used. Root $\mathrm{NH}_{4}^{+}$absorbing properties obtained by Wang et al. (1993) were used. These were $\mathrm{F}_{\text {max }}=2.0 \mathrm{nmol} \mathrm{dm}{ }^{-2} \mathrm{~s}^{-1}$ and $\mathrm{K}_{\mathrm{m}}$ $=32 \mu \mathrm{M}$. The depth containing $63 \%$ of the roots was approximately $2 \mathrm{dm}$, giving $\beta=$ $0.5 \mathrm{dm}^{-1}$.

The concentration of $\mathrm{NH}_{4}^{+}$in solution at the root surface, $\mathrm{C}_{\mathrm{La}}$, in each depth layer required to explain this rate of uptake is then calculated from the mean concentration in solution in the layer, $\mathrm{C}_{\mathrm{L}}$, which is taken to be constant with depth. The corresponding influx per unit root length, $\mathrm{F}$, is found for each depth layer, and, thence, the root length density, $\mathrm{L}_{\mathrm{v}}$, is found. These steps are repeated as necessary if the spread of the depletion zone, $x$, found from $x=2 \sqrt{D t}+a$, exceeds the mean inter-root distance, found from $\mathrm{x}=1 / \sqrt{\pi \mathrm{L}_{\mathrm{v}}}$. If the calculated maximum rooting depth exceeds the depth of the soil core, the distribution of uptake with depth is adjusted pro rata for the 'missing' roots. The total root length density in the soil core is then found from the sum of the values in each depth layer.

Two main assumptions with regard to transport of $\mathrm{NH}_{4}^{+}$to the roots and the form of nitrogen absorbed are made. First, the theory is based on transport of $\mathrm{NH}_{4}^{+}$to the roots solely by diffusion. It does not allow for mass flow of the soil solution towards the roots in the transpiration stream. Kirk \& Solivas (1997) concluded that if mass flow were considered, under similar conditions to those pertaining here, the influx rate would increase by only about $4 \%$. It is, therefore, reasonable to ignore mass flow for the sake of simplicity.

Secondly, it is assumed that $\mathrm{NH}_{4}{ }^{+}$is the only form of nitrogen absorbed by the roots. Under waterlogged conditions, rice roots release some $\mathrm{O}_{2}$ from their internal gas channels into the surrounding anaerobic soil, and, as a result, some of the $\mathrm{NH}_{4}^{+}$near the roots is converted to $\mathrm{NO}_{3}{ }^{-}$by the process of nitrification. Lowland rice roots have an exceptional capacity for absorbing $\mathrm{NO}_{3}$ (Tinker \& Nye, 2000) and, therefore, much of this $\mathrm{NO}_{3}^{-}$is absorbed. Otherwise, it may diffuse away from the roots into the anaerobic soil where it is denitrified to $\mathrm{N}_{2}$ and lost as gas. It is, therefore, not totally correct to assume that all the $\mathrm{N}$ is absorbed as $\mathrm{NH}_{4}^{+}$. However, since nitrification can only occur close to the roots, the $\mathrm{NH}_{4}{ }^{+}$that is nitrified must be transported to the roots and the same limitations apply.

\section{Results}

The model was programmed using FORTRAN 99 and run on a PC. The results obtained are presented and discussed below: 
$\mathrm{NH}_{4}^{+}$concentration in solution

Fig. 1a shows the mean concentrations of $\mathrm{NH}_{4}{ }^{+}$in the soil solution $\left(\overline{\mathrm{C}_{\mathrm{L}}}\right)$ over time for the three water treatments. The order of initial $\overline{\mathrm{C}_{\mathrm{L}}}$ values is flooded $>30 \mathrm{~cm}$ water table $>15 \mathrm{~cm}$ water table; between about 15 and 20 days after treatment imposition, $\overline{\mathrm{C}_{\mathrm{L}}}$ is in the order flooded $=30 \mathrm{~cm}$ water table > $15 \mathrm{~cm}$ water table; between 20 and 25 days the order is flooded $>15 \mathrm{~cm}$ water table $=30 \mathrm{~cm}$ water table. After about 25 days, the order is flooded $>30 \mathrm{~cm}$ water table $>15 \mathrm{~cm}$ water table. In due course as the plants deplete $\mathrm{NH}_{4}^{+}$from the soil all three tend to zero. The order of initial $\overline{\mathrm{C}_{\mathrm{L}}}$ values may reflect differences between the treatments in cation exchange equilibria between the vermiculite (which is initially saturated with $\mathrm{NH}_{4}^{+}$and $\mathrm{Ca}^{2+}$ ) and the differing volumes of nutrient solution.

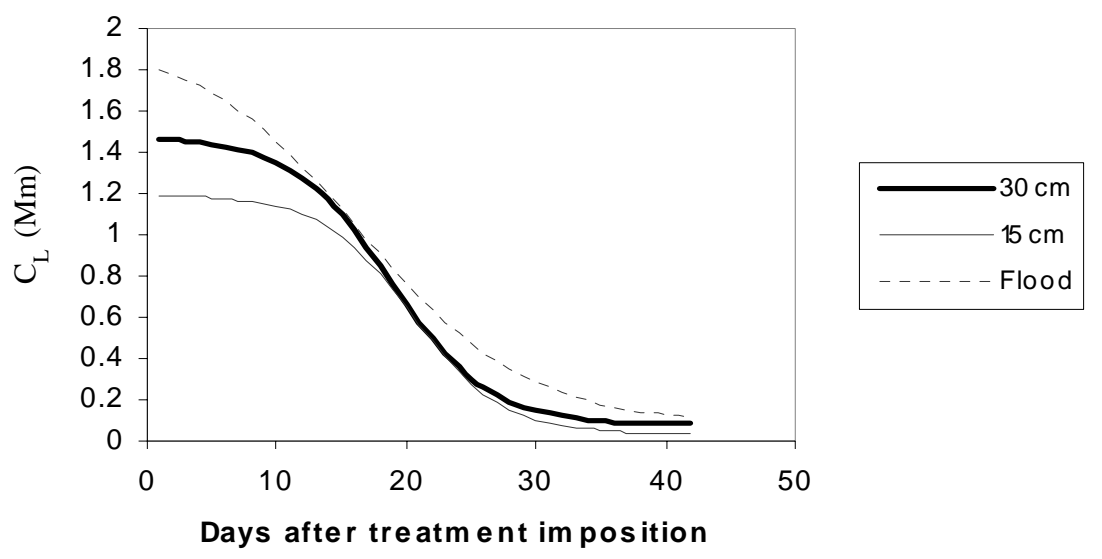

Fig. 1a. Mean concentration of $\mathrm{NH}_{4}^{+}$in the soil solution $\left(\mathrm{C}_{\mathrm{L}}\right)$ over time for the three water treatments

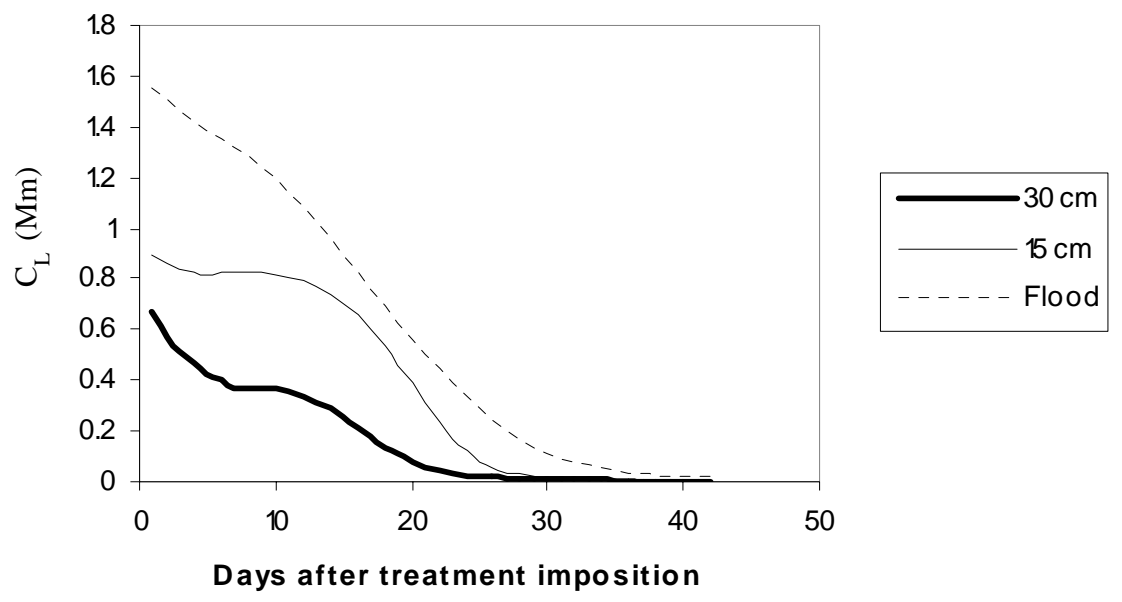

Fig. 1b. Concentrations of $\mathrm{NH}_{4}^{+}$in the soil solution for the three water treatments: (a) the mean bulk soil value $\left(\overline{C_{L}}\right)$, (b) the value at the root surface $\left(\mathrm{C}_{\mathrm{La}}\right)$.

West African Journal of Applied Ecology, vol. 16, 2009 
At the root surface, however, the $\mathrm{NH}_{4}^{+}$ concentration is very different from that in the bulk solution. In this case, the order is flooded $>15 \mathrm{~cm}$ water table $>30 \mathrm{~cm}$ water table. Concentration at the root surface of the $30 \mathrm{~cm}$ water table treatment is about zero about 27 days after treatment imposition; that for the $15 \mathrm{~cm}$ treatment is zero about 32 days but, in the case of the flooded treatment, it is zero at about 41 days after treatment imposition. This is understandable as in terms of total $\mathrm{NH}_{4}^{+}$ available, the order will be flooded $>15 \mathrm{~cm}$ water table $>30 \mathrm{~cm}$ water table. Thus, even with uptake and any other processes that utilize $\mathrm{NH}_{4}^{+}$it is expected that at every point, amounts of $\mathrm{NH}_{4}^{+}$available will be in the order indicated above. and calculated root length densities appeared after 40 days. In the case of the saturated treatment, however, significant differences appear after about 30 days.

Fig. 4 shows the calculated root length on larger-scale axes, and shows that it followed the pattern of uptake rates (Fig. 2) fairly well for the flooded treatment; in the case of the $15 \mathrm{~cm}$ treatment, similarities in the patterns end after about 25 days after treatment imposition; in the case of the 30 $\mathrm{cm}$ treatment, however, the similarities between the two plots end only about 20 days after treatment imposition.

\section{Discussion}

According to Kirk \& Kronzucker (2005) the $\mathrm{N}$ content of a plant determines the uptake characteristics of the roots. At small $\mathrm{N}$ levels,

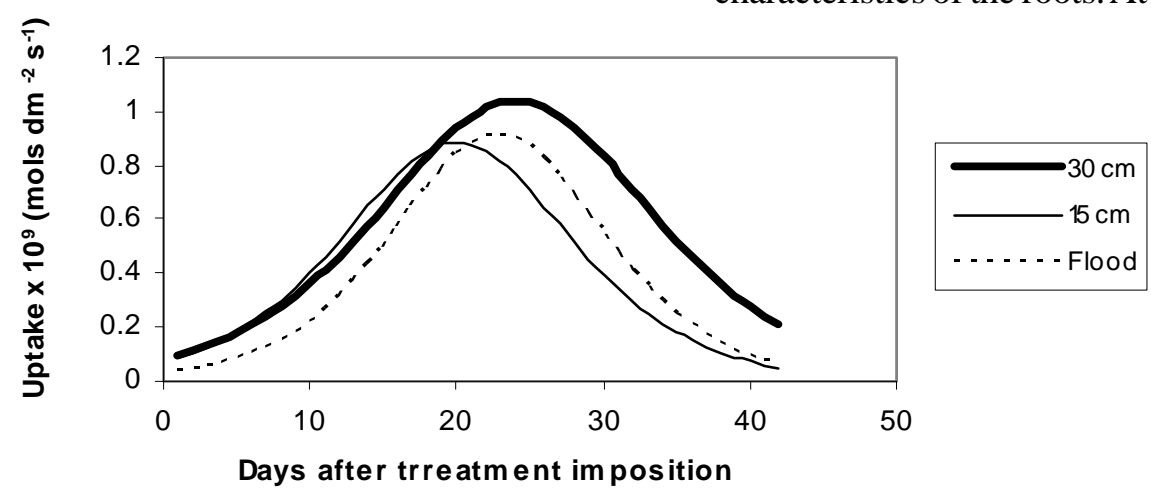

Fig. 2 Rates of $\mathrm{NH}_{4}^{+}$uptake by the plants at $10 \mathrm{~cm}$ depth calculated from the differentiated logistic curve (Equation 12)

\section{Root length densities $\left(L_{v}\right)$}

Fig. 3 shows the measured root length densities at different times in the different treatments and the calculated minimum root length densities required to explain the $\mathrm{NH}_{4}^{+}$ uptake. In the $30 \mathrm{~cm}$ and $15 \mathrm{~cm}$ water table depth treatments, it can be seen that significant differences between measured uptake is maximal; as $\mathrm{N}$ levels increase, uptake is suppressed, and this is depicted by smaller $\mathrm{F}_{\max }$ values and larger $\mathrm{K}_{\mathrm{M}}$ values. As indicated, the values for $\mathrm{K}_{\mathrm{M}}$ and $\mathrm{F}_{\text {max }}$ are taken from studies for roots grown in $2 \mu \mathrm{M}$ solutions. It is clear from Equation 3 that as $\mathrm{F}_{\text {max }}$ decreases and $\mathrm{K}_{\mathrm{M}}$ increases, the root absorbing power, $\alpha$, decreases and there is 


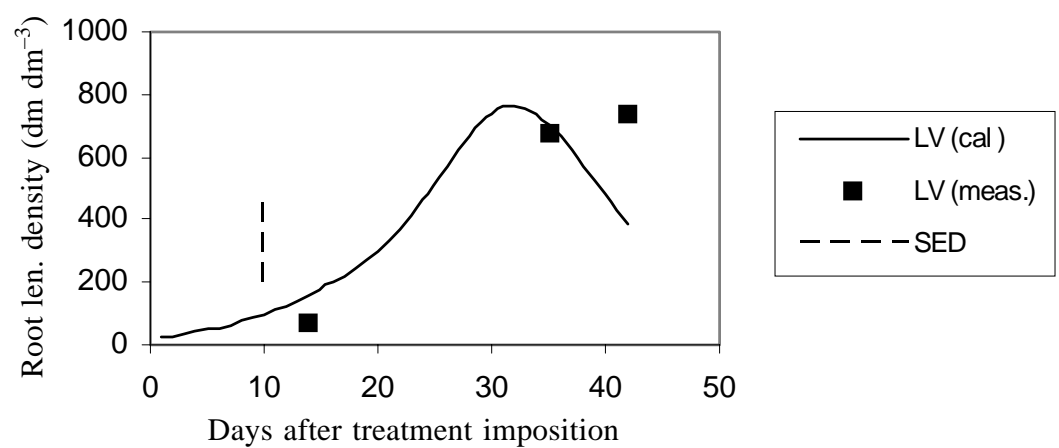

Fig. 3a. Measured root length densities (points) and calculated minimum values required to explain uptake of $\mathrm{NH}_{4}^{+}$(lines) for the $30 \mathrm{~cm}$ water treatment

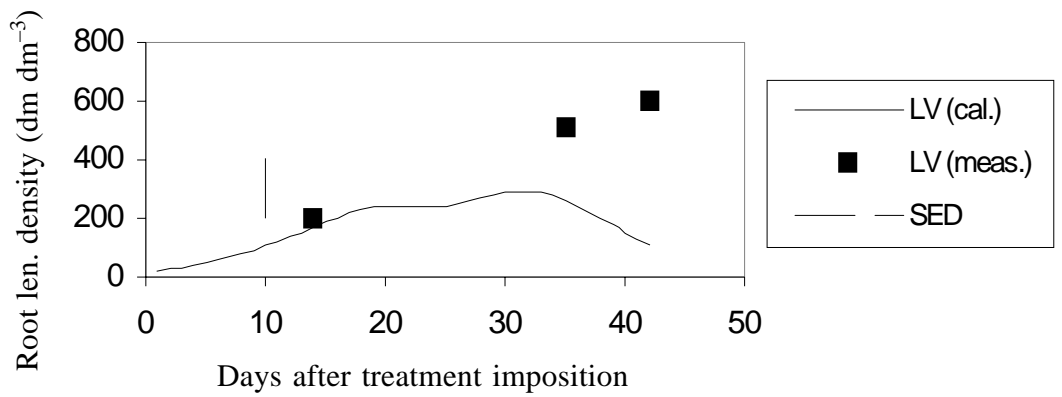

Fig. 3b. Measured root length densities (points) and calculated minimum values required to explain uptake of $\mathrm{NH}_{4}^{+}$(lines) for $15 \mathrm{~cm}$ depth water treatment

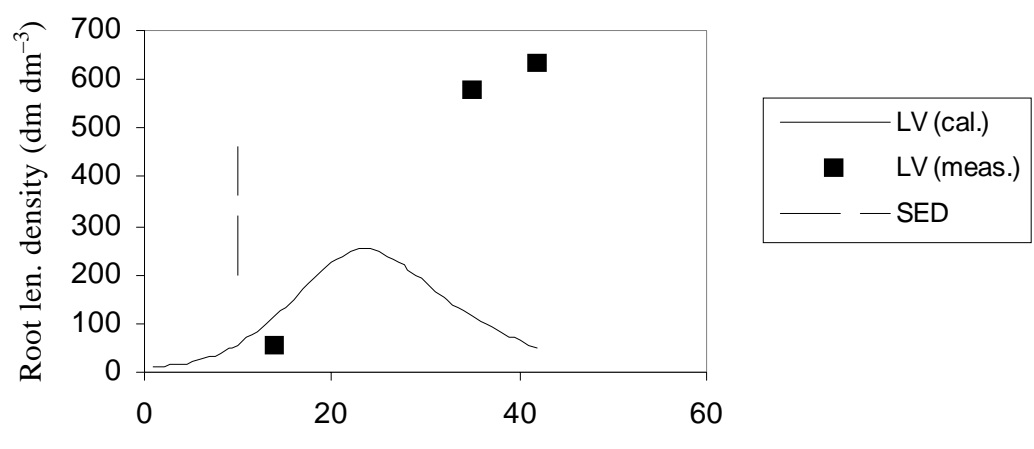

Days after treatment imposition

Fig. 3c. Measured root length densities (points) and calculated minimum values required to explain uptake of $\mathrm{NH}_{4}^{+}$(lines) for flooded treatment

West African Journal of Applied Ecology, vol. 16, 2009 


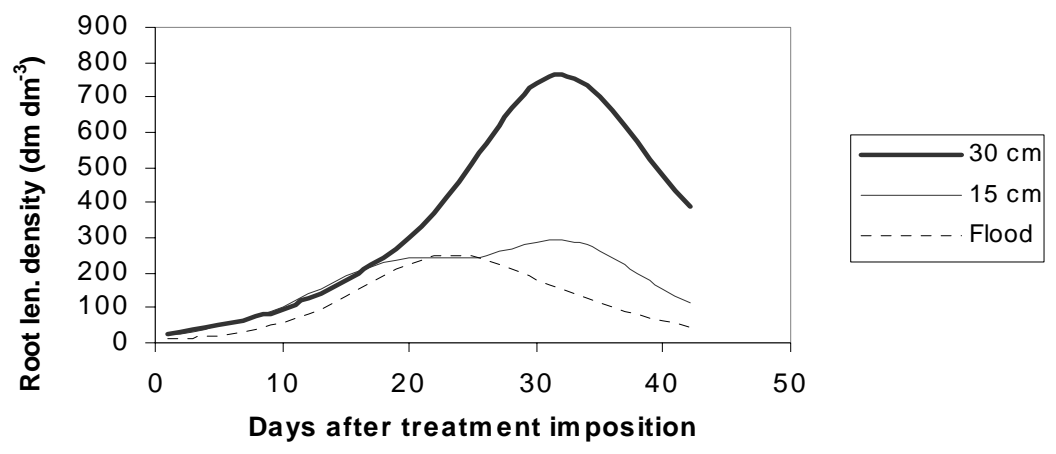

Fig. 4. Calculated minimum root length densities for the three treatments

a corresponding decrease in influx, reflected in increasing $\mathrm{C}_{\mathrm{La}}$, and a larger $\mathrm{L}_{\mathrm{v}}$ is required to maintain the intake rate. Equation 1 also indicates the rate of uptake is sensitive to the mean radius of the roots. A radius of $0.11 \mathrm{~mm}$ was assumed for the calculations. The under-prediction of $\mathrm{L}_{\mathrm{v}}$ (see Fig. 3) as moisture levels increased may, thus, have been due to inappropriate root radius or $\mathrm{F}_{\text {max }}$ and $\mathrm{K}_{\mathrm{M}}$ values or both. Furthermore, the actual root length involved in uptake may have been only a small portion of the total root length as is generally observed for plant root systems (Marschner, 1995).

Over time, $\mathrm{NH}_{4}^{+}$is extracted from the vermiculite as it is removed from the soil by plant uptake and possibly also by nitrificationdenitrification and $\mathrm{NH}_{3}$ volatilisation. The latter is expected only if the $p \mathrm{H}$ rises well above neutral. Nitrification-denitrification may be important where there is an oxicanoxic interface, as there would be if the water-saturated soil became anaerobic. However, measurements of redox potentials in the cores showed that this did not happen (Owusu-Sekyere, 2005) and so nitrificationdenitrification losses were probably minimal.

Fig. $1 \mathrm{~b}$ shows the calculated changes in concentration at the root surface $\left(\mathrm{C}_{\mathrm{La}}\right)$. The values vary with depth but only those at 10 $\mathrm{cm}$ depth are shown for simplicity (the values of $\bar{C}_{L}$ are taken to be independent of depth). After about 20 days the changes in concentration at the root surface over time follow similar patterns to the changes in $\overline{\mathrm{C}_{\mathrm{L}}}$ : they decline as the plants extract $\mathrm{NH}_{4}{ }^{+}$and the rates of decline reflect the rates of uptake. However, in the earlier stages, after an initial sharp drop, $\mathrm{C}_{\mathrm{La}}$ is constant somewhat over time in the unsaturated water treatment, and the difference $\overline{\mathrm{C}_{\mathrm{L}}}-\mathrm{C}_{\mathrm{La}}$, which indicates the concentration gradient required to drive diffusion through the soil to the roots is maintained. This presumably reflects a rate of uptake (dU/dt, shown in Fig. 2 for 10 $\mathrm{cm}$ depth). The difference $\overline{\mathrm{C}}_{\mathrm{L}}-\mathrm{C}_{\mathrm{La}}$ increases as the moisture content decreases between water treatments, and diffusion becomes increasingly limiting.

The measured root length densities decrease in the order: ' $30 \mathrm{~cm}$ ' > ' $15 \mathrm{~cm}$ '> flooded. This is in agreement with the increasing limits on root length imposed by the need for internal aeration under watersaturated conditions, and also with the decreasing soil diffusion limitations for $\mathrm{NH}_{4}^{+}$ uptake as the water content increases. Individual roots are shorter under the wetter 
moisture conditions, probably reflecting restrictions due to the need for internal gas transport (Owusu-Sekyere, 2005).

The calculated root length densities agree reasonably well with the measured ones, but the accuracy of the prediction increases as moisture content decreases. However, this suggests the model describes the important processes reasonably well and that the parameter values are right. However errors in the assumed values for the root radius and root absorption parameters as moisture levels increased may well have contributed to the under-prediction of root length in the later stages.

\section{Conclusion}

The model predicted accurately root length densities in the case of the $30 \mathrm{~cm}$ treatment. In the case of the $15 \mathrm{~cm}$ and the flooded treatments, the accuracy diminished towards latter growth stages. This was attributed to the root radius and the diffusion parameters used for those treatments. In all the three water treatments, the measured root length densities were either lower or just about the same as the calculated minimum required to match the measured rate of $\mathrm{N}$ uptake with the measured mean concentrations of $\mathrm{NH}_{4}^{+}$ in solution around the roots. As indicated, total root length is mainly made up of the lateral roots, which are the ones, which absorb nutrients, and, thus, root length densities were for the most part above that required to ensure uptake of nutrients. Root length densities, therefore, did not limit uptake of nutrients.

There were large differences between values for the solution $\mathrm{NH}_{4}^{+}$concentration and that for $\mathrm{NH}_{4}^{+}$concentration at the root surface. This indicates there was some limitation in transport of nutrients to the roots. This limitation increased as moisture content decreased. As uptake values were higher for the lower moisture content treatments. however, it is clear that these limitations did not hinder uptake of nutrients. Even though diffusion rates differed amongst the three water treatments, rates of transport of nutrients were not such as could limit uptake.

\section{Acknowlodgement}

The authors expressed their appreciation to Prof. Guy Kirk of Cranfield University who helped develop the model as well as to Lawrence Clark, who made it possible for data to be obtained for the study.

\section{References}

Cassman K. G., Peng S., Olk D. C., Ladha J. K., Reichardt W., Dobermann A. and Singh U. (1997). Opportuinites for increased nitrogen use efficiency from improved resource management in irrigated rice systems. Fld Crops Res. 56: 7-39.

Kirk G. J. D. and Kronzucker H. J. (2005). The potential for nitrification and nitrate uptake in the rhizosphere of wetland plants: a modelling study. Ann. Bot. . 96: 639-643.

Kirk G. J. D. and Solivas J. L. (1997). On the extent to which root properties and transport through the soil limit nitrogen uptake by lowland rice. Eur. J. Soil Sci. 48: 613-621.

Marschner H. (1995). Mineral Nutrition of Higher Plants, 2nd edn. Academic Press, New York.

Owusu-Sekyere J. D. (2005). Water Control for Rice Production in Ghana. Cranfield University at Silsoe, UK.

Tinker P. B. and Nye P. H. (2000). Solute movement in the rhizosphere. Oxford University Press, Oxford.

Wang Y. M., Siddiqui M. Y., Ruth T. J. and Glass A. D. M. (1993). Ammonium uptake by rice roots. II Kinetics of ${ }^{13} \mathrm{NH}_{4}^{+}$influx across the plasmalemma. Pl. Physiol. 103: 1259-1267. 